Document downloaded from:

http://hdl.handle.net/10251/83260

This paper must be cited as:

Payri Marín, R.; López Sánchez, JJ.; Marti-Aldaravi, P.; Giraldo Valderrama, JS. (2016). Effect of turbulent model closure and type of inlet boundary condition on a Large Eddy Simulation of a non-reacting jet with co-flow stream. International Journal of Heat and Fluid Flow. 61:545-552. doi:10.1016/j.ijheat\&\#64258;uid\&\#64258;ow.2016.06.016.

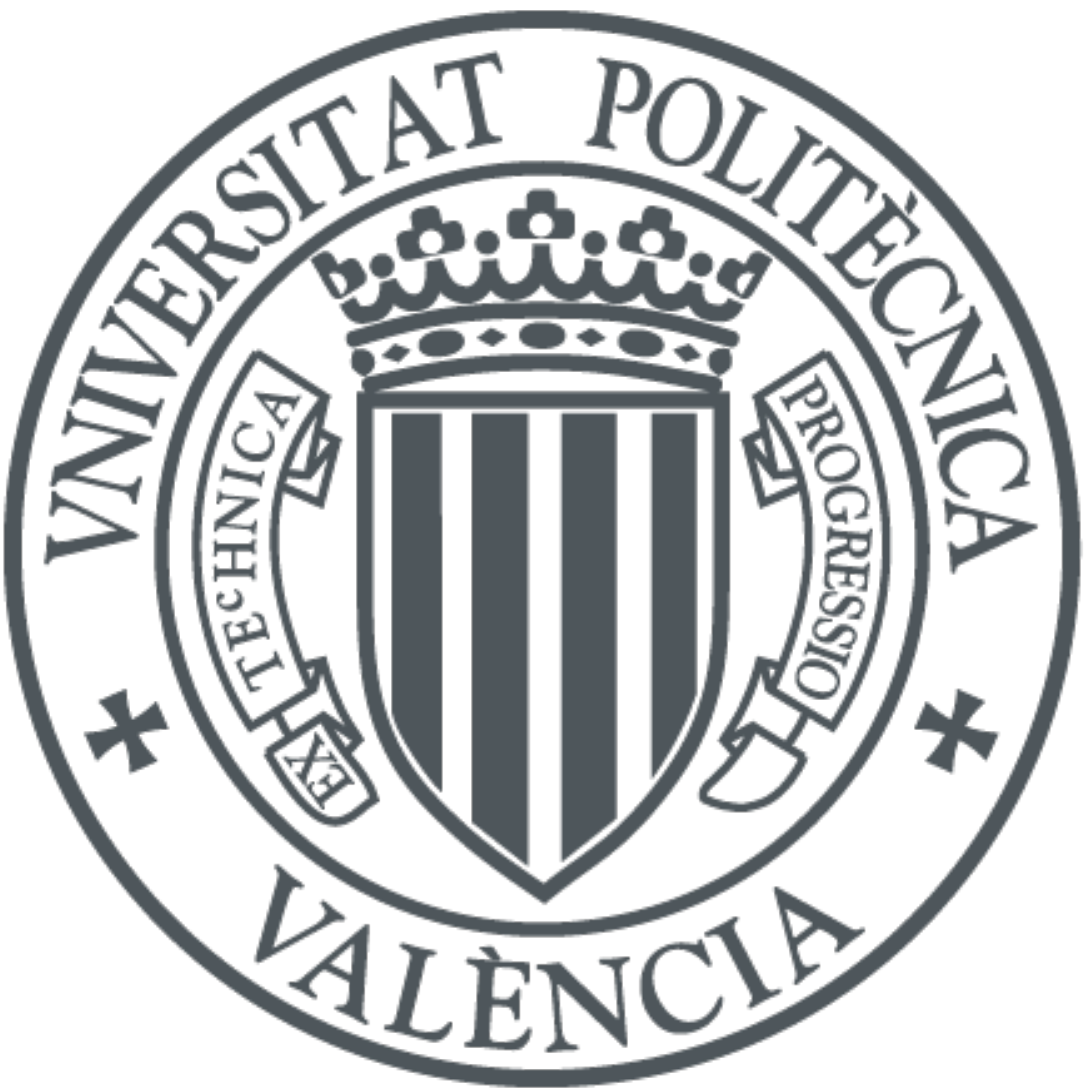

The final publication is available at

http://doi.org/10.1016/j.ijheatfluidflow.2016.06.016

Copyright Elsevier

Additional Information 
Raúl Payri, J. Javier López, Pedro Martí-Aldaraví, Jhoan S. Giraldo, Effect of turbulent model closure and type of inlet boundary condition on a Large Eddy Simulation of a non-reacting jet with co-flow stream, International Journal of Heat and Fluid Flow, Volume 61, Part B, October 2016, Pages 545-552, http://dx.doi.org/10.1016/j.ijheatfluidflow.2016.06.016.

\title{
Effect of turbulent model closure and type of inlet boundary condition on a Large Eddy Simulation of a non-reacting jet with co-flow stream
}

\author{
Raul Payri*, J. Javier López, Pedro Marti-Aldaravi, Jhoan S. Giraldo \\ CMT - Motores Térmicos, Universidad Politécnica de Valencia, Edificio 6D, 46022, Valencia, Spain
}

\begin{abstract}
In this paper, the behavior and turbulence structure of a non-reacting jet with a coflow stream is described by means of Large Eddy Simulations (LES) carried out with the computational tool OpenFoam. In order to study the influence of the sub-grid scale (SGS) model on the main flow statistics, Smagorinsky (SMAG) and One Equation Eddy (OEE) approaches are used to model the smallest scales involved in the turbulence of the jet. The impact of cell size and turbulent inlet boundary condition in resulting velocity profiles is analyzed as well. Four different tasks have been performed to accomplish these objectives. Firstly, the simulation of a turbulent pipe, which is necessary to generate and map coherent turbulence structure into the inlet of the non-reacting jet domain. Secondly, a structured mesh based on hexahedrons has been built for the jet and its coflow. The third task consists on performing four different simulations. In those, mapping statistics from the turbulent pipe is compared with the use of fluctuating inlet boundary condition available in OpenFoam; OEE and SMAG approaches are contrasted; and the effect of changing cell size is investigated. Finally, as forth task, the obtained results are compared with experimental data. As main conclusions of this comparison, it has been proved that the fluctuating boundary condition requires much less computational cost, but some inaccuracies were found close to the nozzle. Also, both SGS models are capable to simulate this kind of jets with a co-flow stream with exactitude.
\end{abstract}

Keywords: Large eddy simulations, Inlet boundary, Smagorinsky, One equation eddy, OpenFoam

* Corresponding author. Tel.: +34 963877650; fax: +34 963877659. E-mail addresses: rpayri@mot.upv.es (R. Payri), jolosan3@mot.upv.es (J. Javier López), pedmar15@mot.upv.es (P. Marti-Aldaravi), jghi@posgrado.upv.es (Jhoan S. Giraldo). 
Raúl Payri, J. Javier López, Pedro Martí-Aldaraví, Jhoan S. Giraldo, Effect of turbulent model closure and type of inlet boundary condition on a Large Eddy Simulation of a non-reacting jet with co-flow stream, International Journal of Heat and Fluid Flow, Volume 61, Part B, October 2016, Pages 545-552, http://dx.doi.org/10.1016/j.ijheatfluidflow.2016.06.016.

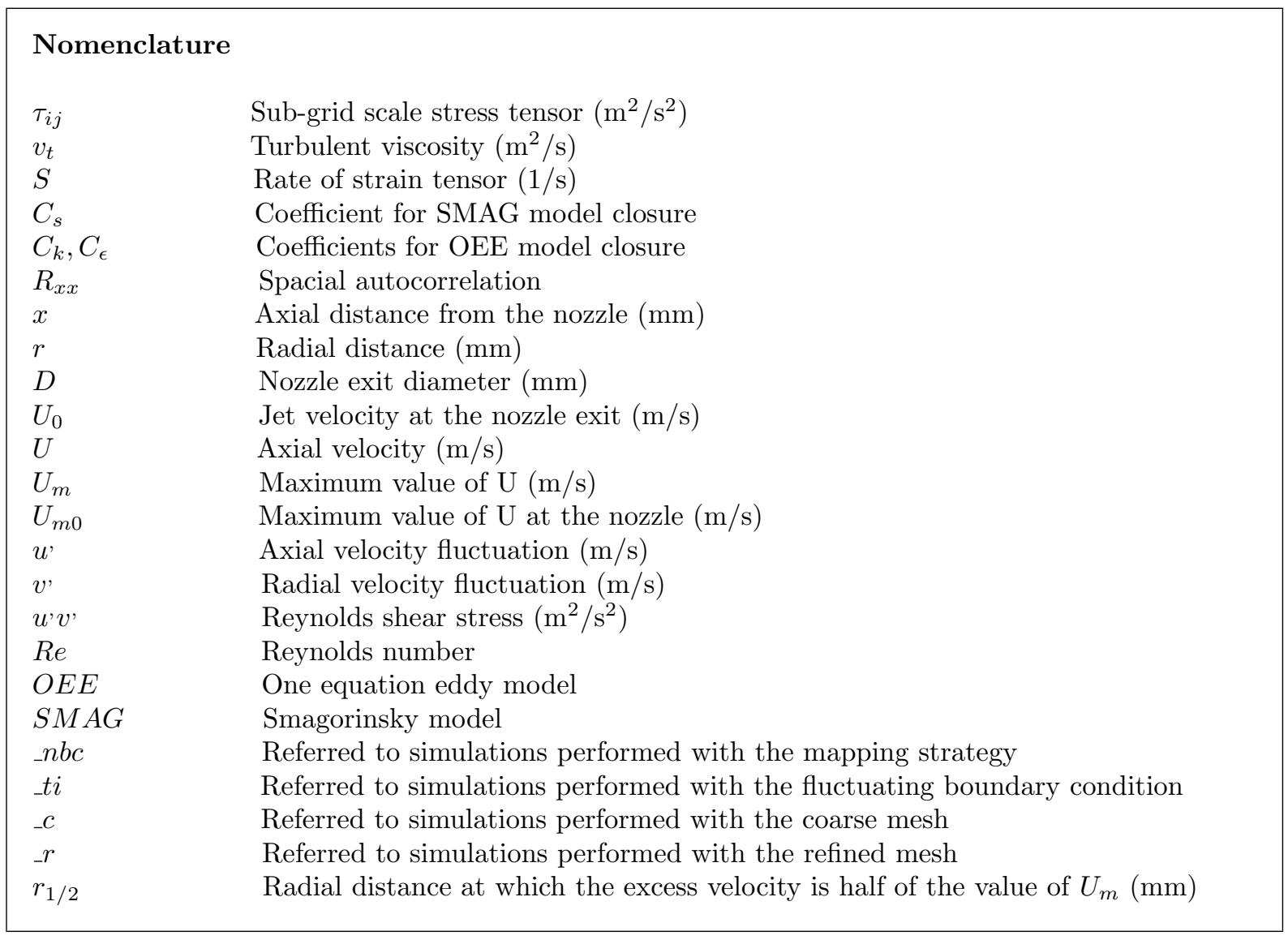

\section{Introduction}

Nowadays, research in combustion is linked to applications that can provide alternatives to reduce emissions and increase process efficiencies. Taking advantage of the gases produced by combustion is a good way to achieve those targets. Recirculating gas combustion products have shown to be useful in order to reduce NOx emissions by diluting the mixture and thus controlling temperature levels [1]. Flame stabilization is improved as well as NOx emissions due to the thermal energy carried by these gases, which act as the enthalpy source needed for ignition [2, 3]. Cabra et al. [4] [5], in their proposal on lifted flames with a co-flow based on combustion products seems to be a successful implementation in order to study flame stabilization by burnt gases. Due to the large experimental database, besides the sensitivity of the flame characteristics to operating conditions, this flame configuration has gained particular interest in the computational combustion community, and is frequently used for validation and development of combustion models [6]. The studies on Large Eddy Simulations (LES) in this kind of flame have been reported in literature [7-13], most of them focusing on Smagorinsky turbulence model closure. LES simulations are not common on these flames due to the cost of implementing detailed chemistry and the inaccuracy of infinitely fast chemistry approaches to simulate lifted 
Raúl Payri, J. Javier López, Pedro Martí-Aldaraví, Jhoan S. Giraldo, Effect of turbulent model closure and type of inlet boundary condition on a Large Eddy Simulation of a non-reacting jet with co-flow stream, International Journal of Heat and Fluid Flow, Volume 61, Part B, October 2016, Pages 545-552, http://dx.doi.org/10.1016/j.ijheatfluidflow.2016.06.016.

flames [7]. Avoiding this problem and considering that the study of turbulent flows in inert environments turns out to be a key point to understand the fuel-air mixing process, some works make an effort to study several applications that involve non-reacting turbulent flows 14 16. Inert studies are of great importance in many industrial processes which include combustion systems, such as rocket engines, gas turbines, industrial furnaces and internal combustion engines [17]. The inert study of this flame helps to focus only on the problem of turbulence, which is one of the most influential phenomena in combustion. Turbulence increases the mixing process and enhances combustion [18]. Inert calculations are the first step before simulating reactive cases.

This paper carries out LES on a non-reacting jet with a co-flow stream that emulates an inert Cabra's experiment considering two different ways of turbulence modeling closure, Smagorinsky (SMAG) and One equation Eddy (OEE). A turbulent pipe is simulated in order to map its fields in the non-reacting jet domain. The results gathered by this strategy are contrasted with resulting velocity profiles from the simulation using a fluctuating inlet boundary condition. Also, the impact of the cell size is analyzed. Since turbulence is a chaotic phenomenon the solution of two LES calculations should be different. Nonetheless, its velocity statistics, e.g. perturbation velocity root mean square, can be comparable [19]. The simulations are also compared with experimental data.

\section{Description of the study}

The burner consists of a round fuel jet issuing into a co-flow of $\mathrm{H}_{2}$ combustion products. The vitiated stream is obtained from hydrogen/air lean premixed combustion and it is composed of $\mathrm{H}_{2} \mathrm{O}$ and air [5]. The central jet mixture consist of $30 \% \mathrm{H}_{2}$ and $70 \% \mathrm{~N}_{2}$, by volume. The bulk velocity of the fuel jet and of the co-flow velocity are of the order of $100 \mathrm{~m} / \mathrm{s}$ and $5 \mathrm{~m} / \mathrm{s}$ respectively. Table 1 summarizes the boundary conditions used in this work as well as the boundary conditions used in the experimental work developed by $\mathrm{Wu}$ et al. 20], who studied the turbulence phenomena related with the experiment in non-reacting and reacting conditions. LES results are compared with experimental data from Cao et al. 21] as well. For simulations, the main flow and the co-flow are considered to be the same specie with the same kinematic viscosity $\left(2.07 \times 10^{-} 5 \mathrm{~m}^{2} / \mathrm{s}\right)$. In order to reach an equivalent Reynolds number of $R e=18600$ in the co-flow stream, the velocity is calculated with the aforementioned viscosity and results $U_{0}=1.84 \mathrm{~m} / \mathrm{s}$. 
Raúl Payri, J. Javier López, Pedro Martí-Aldaraví, Jhoan S. Giraldo, Effect of turbulent model closure and type of inlet boundary condition on a Large Eddy Simulation of a non-reacting jet with co-flow stream, International Journal of Heat and Fluid Flow, Volume 61, Part B, October 2016, Pages 545-552, http://dx.doi.org/10.1016/j.ijheatfluidflow.2016.06.016.

Table 1: General boundary conditions.

\begin{tabular}{lcccccc}
\hline & \multicolumn{2}{c}{ Experimental } & \multicolumn{2}{c}{ Experimental } & \multirow{2}{*}{ This work } \\
& Wu et al. [20] & \multicolumn{2}{c}{ Cao et al. [21] } & & \\
\cline { 2 - 6 } & flow & co-flow & flow & co-flow & flow & co-flow \\
\hline$R e$ & 31500 & 17300 & 23600 & 18600 & 23600 & 18600 \\
$U_{0}(\mathrm{~m} / \mathrm{s})$ & 106 & 1.4 & 107 & 3.5 & 107 & 1.84 \\
$\phi(\mathrm{mm})$ & 4.57 & 190 & 4.57 & 210 & 4.57 & 210 \\
\hline
\end{tabular}

\section{Turbulence modelling}

The simulations have been performed with the open-source code OpenFoam. The solver for transient incompressible flows resolves Navier-Stokes equations enforced with a merged PISO-SIMPLE algorithm. It is based on an Eulerian formulation. A finite-volume discretization with second-order central schemes for convection and diffusion terms is employed. Temporal discretization is performed with an implicit second order scheme. This solver first sets the boundary conditions, then solves the discretized momentum equation to compute an intermediate velocity field, computes the mass fluxes at cell faces and lastly the pressure equation is solved.

LES decompose the flow variables into resolved and sub-grid scale terms. The resolved scales are calculated by means of the transport equations, meanwhile the sub-grid scales terms are modelled [22 24]. Both filtered variables and sub-grid scale variables are dependent of the filter size and the impact of the modeling should decrease as the filter size decrease. With the filtering procedure the momentum equation becomes:

$$
\frac{\partial \bar{u}_{i}}{\partial t}+\frac{\partial \bar{u}_{j} \bar{u}_{i}}{\partial x_{j}}=-\frac{\partial \bar{P}}{\partial x_{i}}+\nu \frac{\partial^{2} \bar{u}_{i}}{\partial x_{j} \partial x_{j}}-\frac{\partial \tau_{i j}}{\partial x_{j}}
$$

where the variable $\bar{P}$ also includes volumetric forces, and the SGS stress tensor is:

$$
\tau_{i j}=\overline{u_{i} u_{j}}-\overline{u_{i} u_{j}}
$$

The SGS tensor cannot be determined by the resolved scales, therefore it has to be modelled (system closure). This work uses two kind of turbulence model closures: the Smagorinsky approach (SMAG) 25] and the one equation eddy approach (OEE) [22]. A brief description of both is given in the following subsections.

\subsection{Smagorinsky approach (SMAG)}

It is an algebraic model (or zero equation model), which means that there is no transport equation required to calculate the turbulent eddy viscosity [26]. The model obtains the sub-grid stress term as a function of turbulent viscosity and the strain rate. 
Raúl Payri, J. Javier López, Pedro Martí-Aldaraví, Jhoan S. Giraldo, Effect of turbulent model closure and type of inlet boundary condition on a Large Eddy Simulation of a non-reacting jet with co-flow stream, International Journal of Heat and Fluid Flow, Volume 61, Part B, October 2016, Pages 545-552, http://dx.doi.org/10.1016/j.ijheatfluidflow.2016.06.016.

$$
\tau_{i j}-\frac{1}{3} \delta_{i j} \tau_{k k}=-2 \nu_{t} S_{i j}
$$

where $S_{i j}$ is the rate-of-strain tensor and $\nu_{t}$ is the turbulent viscosity, both given by:

$$
\begin{gathered}
S_{i j}=\frac{1}{2}\left(\frac{\partial u_{i}}{\partial x_{j}}+\frac{\partial u_{j}}{\partial x_{i}}\right) \\
\nu_{t}=C_{s} \Delta^{2} \sqrt{2 \overline{S_{i j}} \overline{S_{j i}}}
\end{gathered}
$$

In this last equation, $C_{s}$ is the Smagorinsky constant, which has a theoretical value in the range [0.1-0.2] [27]. The value of $C_{s}$ finally selected in this study is the default value defined in OpenFoam $\left(C_{s}=0.2\right)$. Also, $\Delta$ is the filter width, computed as the cubic root of the cell volume.

\subsection{One equation eddy approach (OEE)}

The net quantity of the dissipation from resolved scales is correct in the SMAG approach, but the energy locally dissipated might be incorrect [22]. For this reason, models such as OEE become important. Like for the SMAG approach, this model is also based on the definition of turbulent viscosity $\nu_{t}$, and it assumes that the stress tensor is proportional to the strain stress tensor. It introduces an extra transport equation, but for the sub-grid turbulent kinetic energy $\left(k_{s g s}=\tau_{k k} / 2\right)$. It has been demonstrated that this strategy may improve the modeling of the sub-grid scales, allowing coarser meshes [22]. The additional transport equation for incompressible flows is:

$$
\frac{\partial k_{s g s}}{\partial t}+\frac{\partial\left(u_{j} k_{s g s}\right)}{\partial x_{j}}=\frac{\partial}{\partial x_{j}}\left(\left(\nu+\nu_{t}\right) \frac{\partial k_{s g s}}{\partial x j}\right)-\tau_{i j} \overline{S_{i j}}-\varepsilon
$$

where the viscous dissipation is usually taken as:

$$
\varepsilon=C_{\varepsilon}\left(\frac{k_{s g s}^{3 / 2}}{\Delta}\right)
$$

the sub-grid viscosity is modeled as:

$$
\nu_{t}=C_{k} k_{s g s}^{1 / 2} \Delta
$$

and finally, the sub-grid stress tensor is calculated as follows:

$$
\tau_{i j}=-2 \nu_{t} \overline{S_{i j}}+\frac{2}{3} \delta_{i j} k_{s g s}
$$

The coefficients can be evaluated based on turbulence theory or adjusted dynamically. In this case, $C_{k}=0.094$ and $C_{\varepsilon}=1.048$, which are the default values given by the code. 
Raúl Payri, J. Javier López, Pedro Martí-Aldaraví, Jhoan S. Giraldo, Effect of turbulent model closure and type of inlet boundary condition on a Large Eddy Simulation of a non-reacting jet with co-flow stream, International Journal of Heat and Fluid Flow, Volume 61, Part B, October 2016, Pages 545-552, http://dx.doi.org/10.1016/j.ijheatfluidflow.2016.06.016.

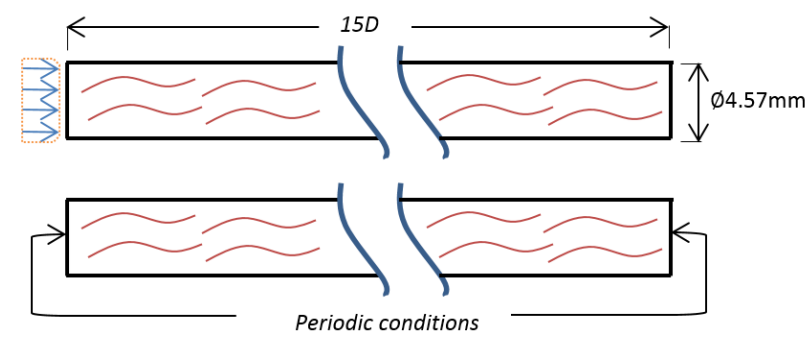

Figure 1: Boundary conditions for the turbulent pipe.

\subsection{Turbulent pipe}

\subsubsection{Mesh and mapping strategy description} 28 . with similar reynolds numbers [29, 30].

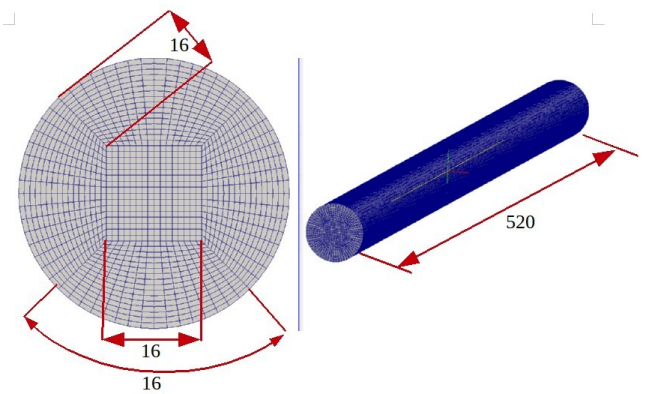

Figure 2: Cell distribution of the turbulent pipe.

\section{Case set-up and numerical implementation}

One of the aims of this work is to compare how velocity statistics of the Cabra jet change using two different inlet boundary conditions. In the first case, a fluctuating boundary condition available in OpenFoam was established. In the second case, the inlet condition was pre-simulated in a turbulent pipe, and transient velocity of that case was imposed at the inlet of the main flow, thus coherent turbulent structure is ensured. In the following, a description of the turbulent pipe simulation is presented.

The simulation of the turbulent pipe with periodic boundary conditions is carried out in two stages, sketched in Fig. 1. First the domain is filled with stagnated gas, which accelerates due to imposed inlet velocity. Once the flow reaches the outlet, boundary conditions are switched to cyclic. This allows the flow inside the pipe to reach a fully developed turbulent velocity profile without the necessity of having a very long domain

Subsequently this profile is mapped and imposed as an inlet boundary condition for the non-reacting Cabra jet simulation. The geometry of the turbulent pipe with its cell distribution is shown in Fig. 2. The cylindrical domain has the same inlet diameter $(4.57 \mathrm{~mm})$ of the experiment carried out by Cabra et al. [5]. Its length $(15.3 D=70 \mathrm{~mm})$ was based on the convergence of turbulence statistics of others turbulent pipe simulations

The mesh used in this case (Fig. 2) consists of 665600 cells, 1280 in the radial direction and 520 in axial direction. The minimum cell size is $0.134 \mathrm{~mm}$.

The SGS model was OEE. Once the mean velocity at the center of the domain becomes constant in time, see Fig. 3 after $0.01 \mathrm{~s}$, and two point spatial correlation shows an independence of statistics at $x / D=9$, see Fig. 4, fields are mapped during $30 \mathrm{~ms}$, which is the chosen time to simulate the inert jet. $10 \mathrm{~ms}$ are required to obtain a jet penetration of at least $x / D=50$ in the Cabra jet and 20 ms more (up to 7 flow-through-times) to 
Raúl Payri, J. Javier López, Pedro Martí-Aldaraví, Jhoan S. Giraldo, Effect of turbulent model closure and type of inlet boundary condition on a Large Eddy Simulation of a non-reacting jet with co-flow stream, International Journal of Heat and Fluid Flow, Volume 61, Part B, October 2016, Pages 545-552, http://dx.doi.org/10.1016/j.ijheatfluidflow.2016.06.016.

gather statistics. This timing was defined by collecting information from several similar studies [7, 8, 10, 12].

\subsubsection{LES Quality Assessment for the turbulent pipe}

A probe is located in the center of the domain, where the velocity field will be mapped (at $x=9 D$ ). This probe helped to confirm whether the flow was already turbulent or not. Fig 3 exposes the captured velocity in time and its mean. This confirms that after $0.01 \mathrm{~s}$ the flow is developed. This is also tested by the two point spatial correlation defined as:

$$
R_{x x}=\frac{\sum \overline{u^{\prime}(x) u^{\prime}(x+\Delta x)}}{\sum \overline{u^{\prime}(x) u^{\prime}(x)}}
$$

The two point correlation behavior can be seen in Fig. 4. Statistics between $x / D=1$ and $x / D=14$ seem to be independent from the initial signals. It confirms that statistics taken from $9 D$ could be mapped and used as inlet data for the main domain.

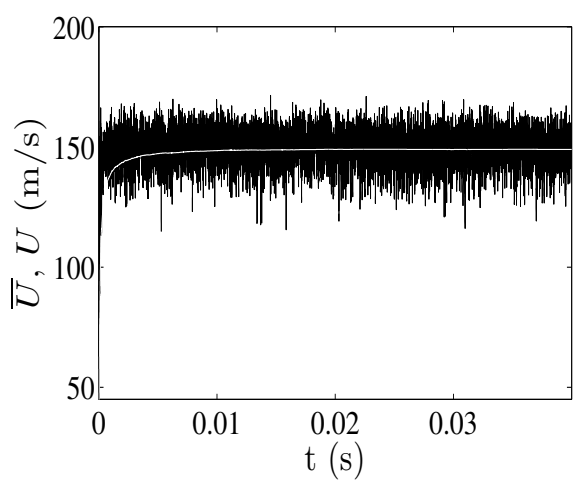

Figure 3: Velocity and its mean (probe located at $9 D$ in the middle of the turbulent pipe).

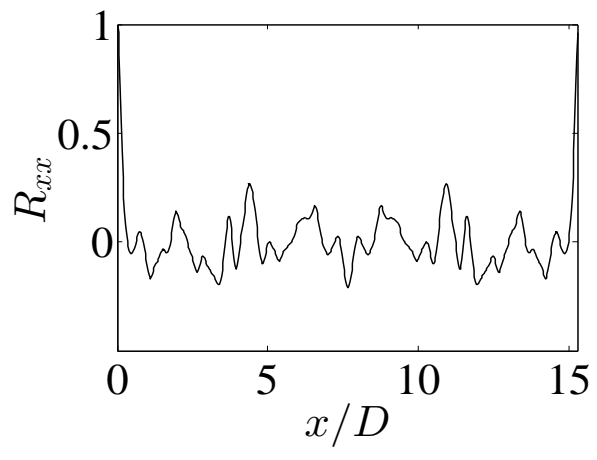

Figure 4: Spatial autocorrelation at 0.01s.

An important issue regarding LES is to know if a sufficient part of the turbulent flow energy is directly resolved by the computational grid. In this case, it is considered that the biggest scales of the flow, whose behavior is difficult to model using a SGS model, are well captured, then conferring a high level of confidence in the LES predictability [31]. Power spectra was computed from the signals of $5 \mathrm{~ms}$ in duration by using a windowed Fourier transform with overlapping segments of $0.5 \mathrm{~ms}$ in length, averaging the spectra over the segments. The results are shown in Fig. 5. Reasonable inertial range spectrum ( $-5 / 3$ law) [32] is recovered, suggesting that the current resolution is acceptable to resolve momentum transport in the shear layer regions. 
Raúl Payri, J. Javier López, Pedro Martí-Aldaraví, Jhoan S. Giraldo, Effect of turbulent model closure and type of inlet boundary condition on a Large Eddy Simulation of a non-reacting jet with co-flow stream, International Journal of Heat and Fluid Flow, Volume 61, Part B, October 2016, Pages 545-552, http://dx.doi.org/10.1016/j.ijheatfluidflow.2016.06.016.

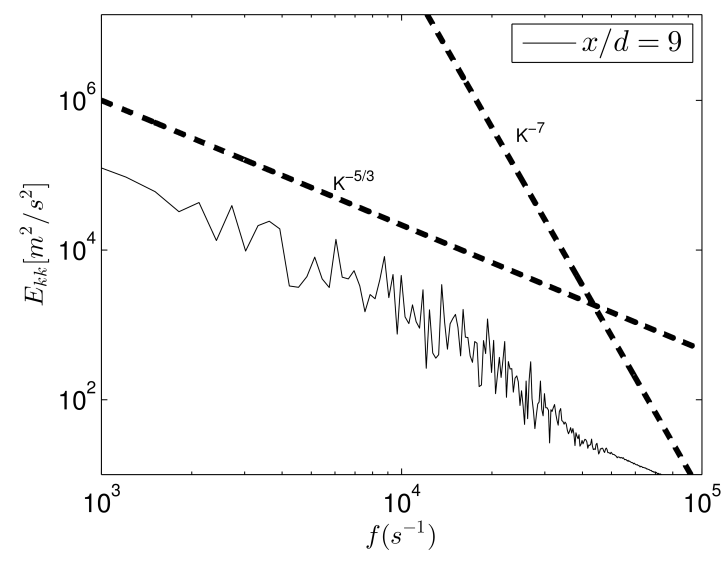

Figure 5: Energy spectra for the turbulent pipe

The mean velocity and its fluctuation profiles of the turbulent pipe are shown in Fig. 6 . These profiles are compared with experimental inlet velocity profiles measured by Kent 33. on the Cabra jet configuration. No differences are observed in the mean velocity whilst a very small difference, of about $0.02 \mathrm{~m} / \mathrm{s}$, is found for fluctuation velocity. The simulation is accurate.
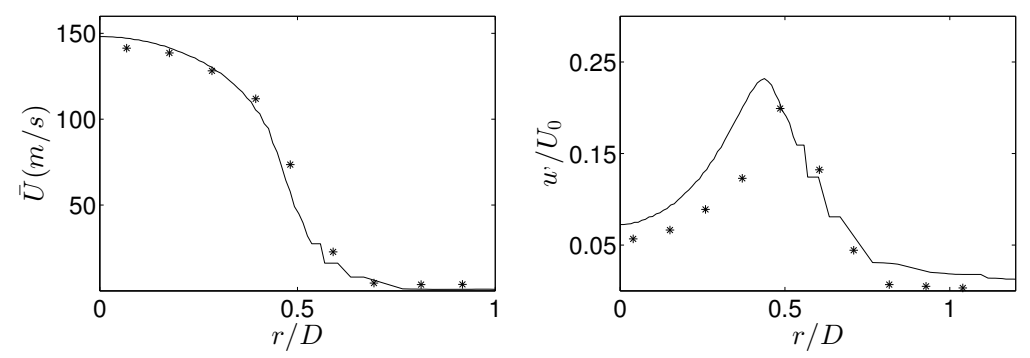

Figure 6: (Solid line) Radial profile of the mean velocity and its fluctuation in the turbulent pipe simulation, (Asterisks) Experimental data from Kent's measurements at $x / D=0$ 33.

\subsection{Main domain - Cabra Jet}

\subsubsection{Base mesh}

The geometry of the domain is based on the experimental configuration of Cabra et al. [5]. This computational cylindrical domain extends radially $\sim 23 D$ and axially $\sim 103 D$. Jones and Navarro-Martinez [8] carried out a brief mesh independence study where resulting velocity statistics from the finest grid $(\sim 1.8$ million of cells) were not converging yet using a similar cylindrical mesh. Because of that, the coarse mesh used in this study adopted is even finer than the finest mesh used by Jones and Navarro-Martinez's work. The coarse grid for this work consists of a structured mesh of $\sim 3.7$ millions 
Raúl Payri, J. Javier López, Pedro Martí-Aldaraví, Jhoan S. Giraldo, Effect of turbulent model closure and type of inlet boundary condition on a Large Eddy Simulation of a non-reacting jet with co-flow stream, International Journal of Heat and Fluid Flow, Volume 61, Part B, October 2016, Pages 545-552, http://dx.doi.org/10.1016/j.ijheatfluidflow.2016.06.016.

hexahedrons. The side view illustrated in Fig. 7 shows the axial cell distribution of the mesh. Blue arrows tips in Fig. 8 indicate the growing direction of the cell size, where $r$ is the "common ratio" since the cell size is varying within a geometric progression. Axially, the domain is divided in two zones (see Fig. 8) with two different values of "common ratio". The minimum cell size is located at the nozzle inlet.

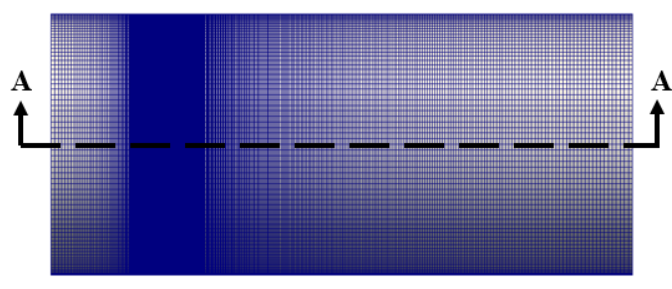

Figure 7: Side view for mesh cell distribution.

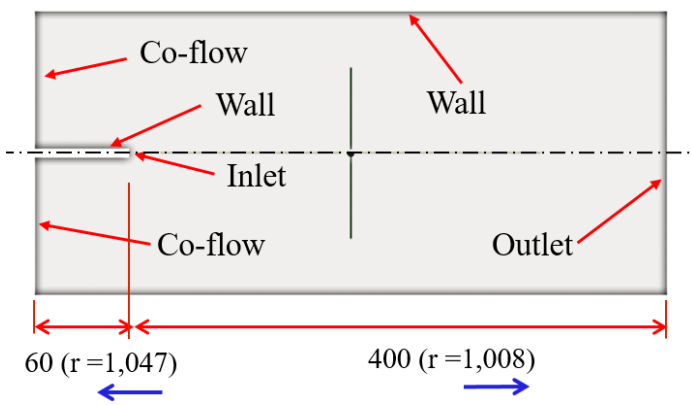

Figure 8: Section A-A of the cylindrical domain. Number of cells, growing size direction and common ratio.

The frontal view for mesh cell distribution is shown in Fig. 9. The mesh core (coreinlet) has the same frontal cell distribution as the domain built for the turbulent pipe (shown in Fig 2) in order to increase mapping process accuracy.
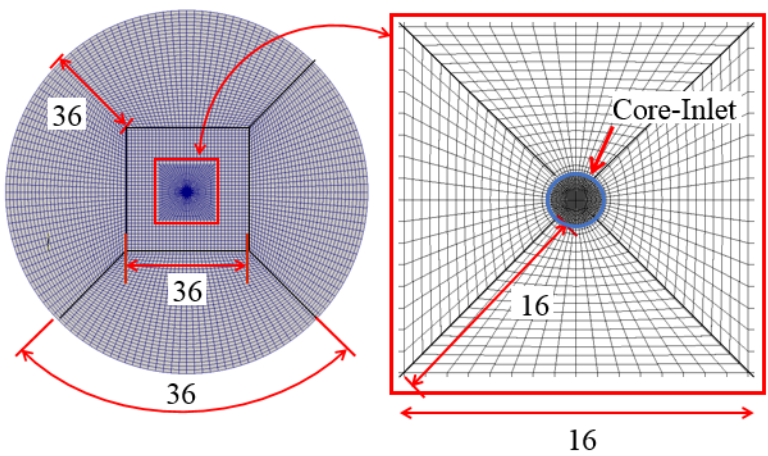

Figure 9: Frontal view for mesh cell distribution. Number of cells in different directions.

\subsubsection{Refined mesh}

The mesh is refined in the zone shown in Fig. 10 in order to find out if velocity statistics are being affected by reducing the cell size. This is also an attempt to obtain more accurate results despite the increase in computational cost. The resulting mesh consist of $\sim 8.3$ millions of hexahedrons, and the cone angle used to refine this zone $\left(20^{\circ}\right)$ was taken from results shown by $\mathrm{Wu}$ et al.[20]. The minimum size for the refined mesh was $0.067 \mathrm{~mm}$. 
Raúl Payri, J. Javier López, Pedro Martí-Aldaraví, Jhoan S. Giraldo, Effect of turbulent model closure and type of inlet boundary condition on a Large Eddy Simulation of a non-reacting jet with co-flow stream, International Journal of Heat and Fluid Flow, Volume 61, Part B, October 2016, Pages 545-552, http://dx.doi.org/10.1016/j.ijheatfluidflow.2016.06.016.

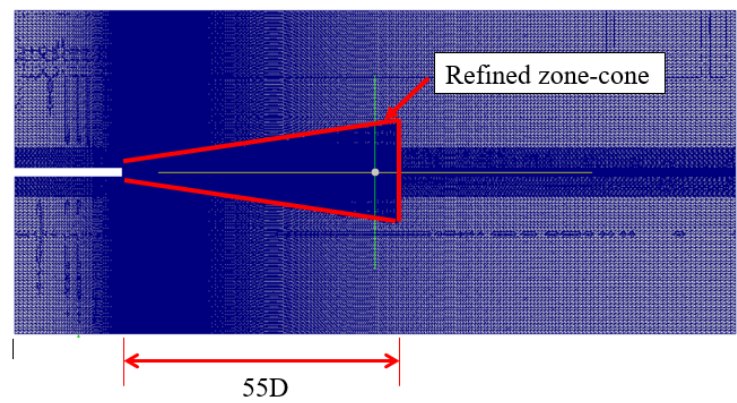

Figure 10: Refined mesh.

\subsubsection{LES quality assessment for the main domain}

Power spectrum was also computed for the coarse and the refined meshes signals, the same energy spectrum averaged by segments with length of $0.5 \mathrm{~ms}$ was calculated for several axial distances from the nozzle, averaging the spectra over the segments. Again, inertial range spectrum ( $-5 / 3$ law) [34] was found, and also a slope of -7 indicating that both meshes were also calculating scales from the dissipation range, suggesting that the current resolutions, even the coarse one, were very fine (Fig. 11, 12.)

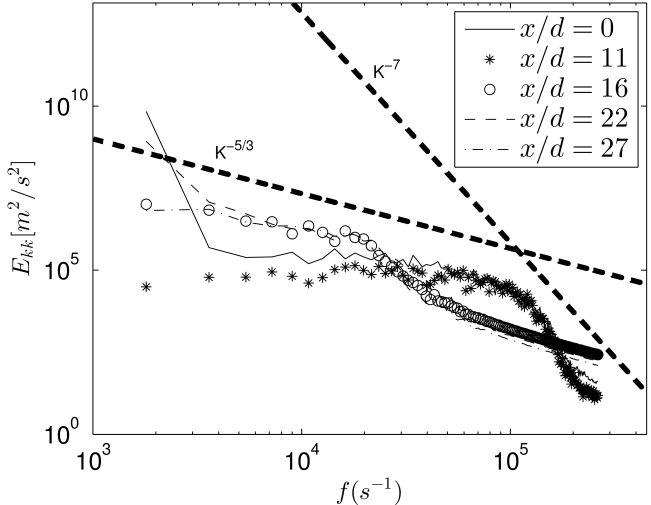

Figure 11: Energy spectra for the coarse mesh

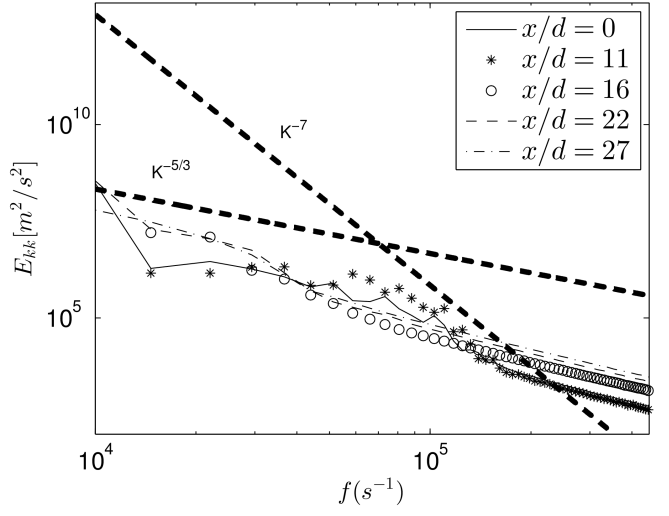

Figure 12: Energy spectra for the refined mesh

\subsection{Computational cost}

Three computer clusters were used for the calculations. One is composed of 24 processors "Intel Xeon E5-4617 @2.90GHz" and 64GB of RAM memory. Other has 24 processors "Intel Xeon E5-2630 @2.60GHz" and 64GB of RAM memory . The last one has 8 processors "Intel Xeon E5504 @2.00GHz" and 8GB of RAM memory. Computational cost per $10 \mathrm{~ms}$ and Courant numbers $C_{0}$ for each simulation are presented in Table 2. The simulations performed with the refined mesh take $\sim 6.5$ more time to achieve admissible results. 
Raúl Payri, J. Javier López, Pedro Martí-Aldaraví, Jhoan S. Giraldo, Effect of turbulent model closure and type of inlet boundary condition on a Large Eddy Simulation of a non-reacting jet with co-flow stream, International Journal of Heat and Fluid Flow, Volume 61, Part B, October 2016, Pages 545-552, http://dx.doi.org/10.1016/j.ijheatfluidflow.2016.06.016.

Table 2: Computational cost, Courant number and calculating machines.

\begin{tabular}{lcccc}
\hline Simulation & $\begin{array}{c}\text { Computational } \\
\text { cost }(\mathrm{hrs} / 10 \mathrm{~ms})\end{array}$ & Calculating machines & $C_{0}$ & Processors \\
\hline turbulent pipe & 66 & $@ 2.00 \mathrm{GHz}$ & 0.85 & 8 \\
OEE_nbc_c & 46 & $@ 2.60 \mathrm{GHz}$ & 0.85 & 24 \\
SMAG_nbc_c & 47 & $@ 2.60 \mathrm{GHz}$ & 0.85 & 24 \\
SMAG_nbc_r & 301 & $@ 2.60 \mathrm{GHz}$ & 0.85 & 24 \\
SMAG_ti_c & 16 & $@ 2.90 \mathrm{GHz}$ & 0.85 & 24 \\
\hline
\end{tabular}

\section{Results}

Table 3 shows axial velocities in the jet center for each simulation at several distances from the nozzle. These magnitudes are used to obtain dimensionless velocity profiles. As it has been said before, the aim of the study is to evaluate how the inlet boundary condition, the model closure and the cell size could affect velocity statistic profiles. In this section, results according to those objectives are displayed.

Table 3: Axial velocity in the jet center $\left(U_{m}[\mathrm{~m} / \mathrm{s}]\right)$ for several $x / D$.

\begin{tabular}{lcccc}
\hline$x / D$ & OEE_nbc_c & SMAG_nbc_c & SMAG_nbc_r & SMAG_ti_c \\
\hline 1 & 148.47 & 148.08 & 147.76 & 141.36 \\
8 & 88.20 & 83.84 & 86.98 & 91.07 \\
10 & 73.8 & 67.85 & 70.53 & 75.06 \\
14 & 52.4 & 51.2 & 49.39 & 59.23 \\
\hline
\end{tabular}

\subsection{Influence of mesh resolution}

In this section, results obtained for the inert jet injected for both meshes (coarse and refined) using the SMAG model closure by using the mapping strategy are presented. This has been done in order to check if the velocity statistics obtained from both meshes are consistent with experimental data. In Fig. 13 it is shown that the velocity decay obtained with both meshes barely changes. This is an indication that the mesh was already fine enough to achieve accurate results. 
Raúl Payri, J. Javier López, Pedro Martí-Aldaraví, Jhoan S. Giraldo, Effect of turbulent model closure and type of inlet boundary condition on a Large Eddy Simulation of a non-reacting jet with co-flow stream, International Journal of Heat and Fluid Flow, Volume 61, Part B, October 2016, Pages 545-552, http://dx.doi.org/10.1016/j.ijheatfluidflow.2016.06.016.

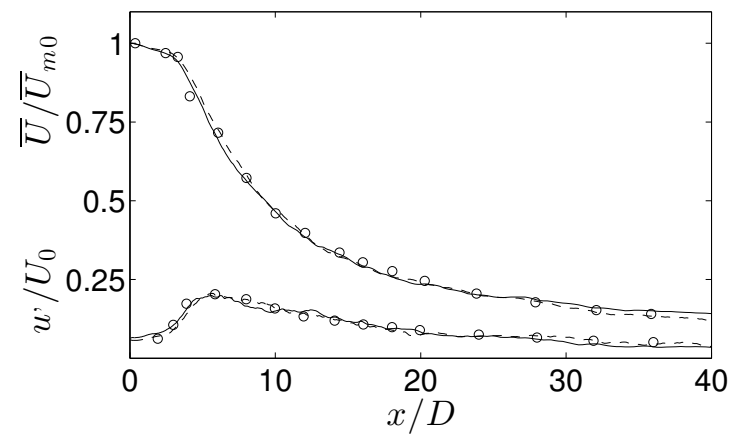

Figure 13: Velocity decay and its fluctuation in the axis direction. (Circles) measurements Wu et al. 20. (Solid line) calculations using the coarse mesh. (Dash line) calculations using the refined mesh.

In Fig. 14 radial velocity profiles and its fluctuations for both meshes are presented. Again. results from both meshes almost fall on one single curve. The small variation in the results also confirms that a mesh refinement was not necessary.
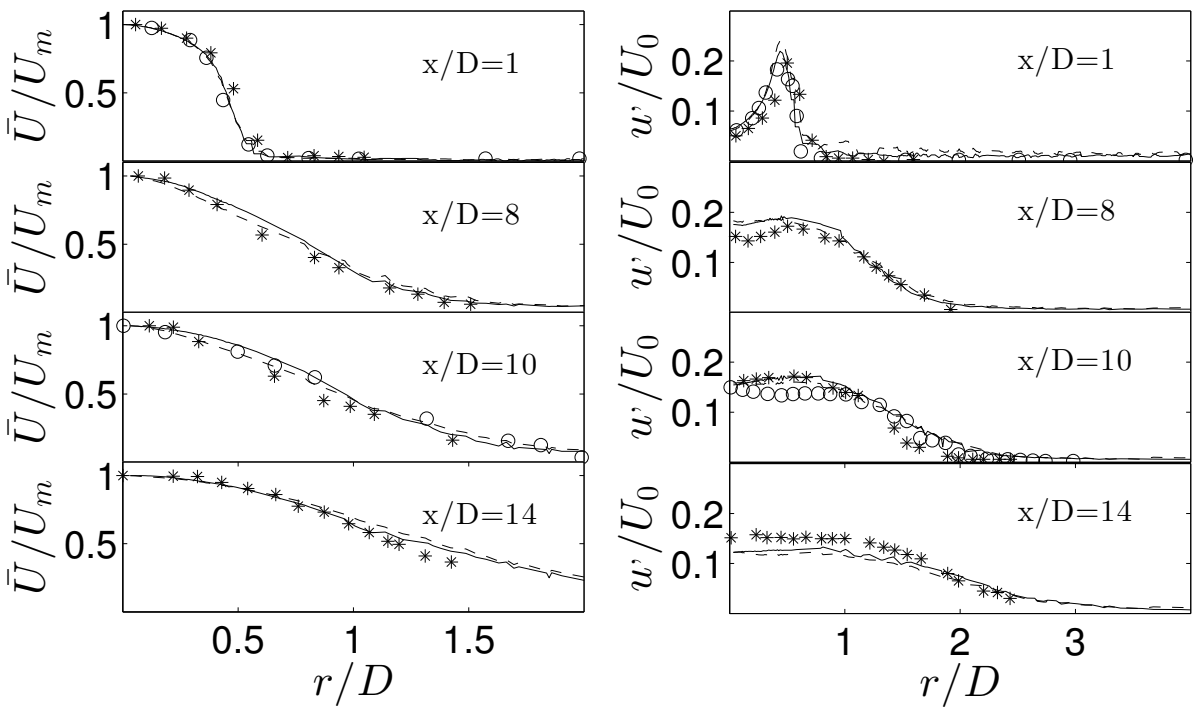

Figure 14: Radial velocity profiles. (Circles) Measurements Wu et al. 20. (Asterisks) Measurements Cao et al. 21]. (Solid line) calculations using the coarse mesh. (Dash line) calculations using the refined mesh.

\subsection{Effect of inlet boundary condition}

In this section, results of different two simulations are shown, they were obtained for the inert jet injected in the coarse mesh, one using the mapping strategy and the other 
Raúl Payri, J. Javier López, Pedro Martí-Aldaraví, Jhoan S. Giraldo, Effect of turbulent model closure and type of inlet boundary condition on a Large Eddy Simulation of a non-reacting jet with co-flow stream, International Journal of Heat and Fluid Flow, Volume 61, Part B, October 2016, Pages 545-552, http://dx.doi.org/10.1016/j.ijheatfluidflow.2016.06.016.

one a fluctuating inlet boundary condition supplied by OpenFoam. SMAG model closure was used. This is done to check which type of inlet boundary condition could reproduce the coherent turbulent structures and velocities more adequately. If the fluctuating inlet boundary condition proves to be useful, it implies less computational cost in future simulations in this kind of jets because the simulation of a turbulent pipe could be avoided.

The velocity decay for the simulation carried out with the mapped and the OpenFoam boundary conditions are shown in Fig. 15. Both simulations are compared as well with experimental data. The velocity decay obtained from the simulation performed with the mapping strategy seems to fit properly with the experimental data. The fluctuating boundary condition tends to over-estimate the velocity decay. Nevertheless, it leads to acceptable results considering its low computational cost, then this kind of boundary condition could be useful.

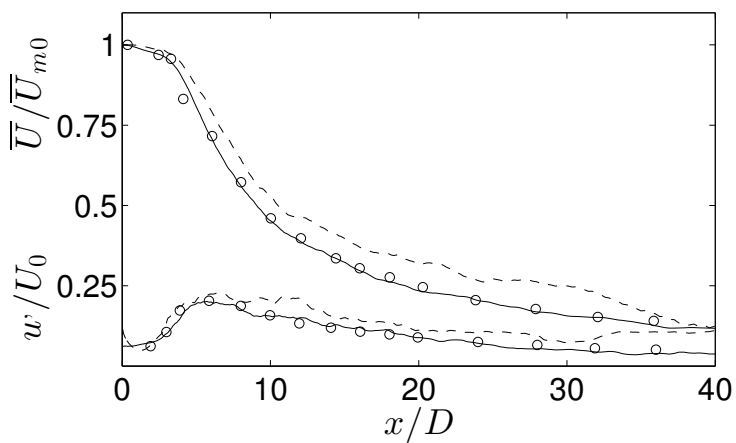

Figure 15: Velocity decay and its fluctuation in the axis direction. (Circles) measurements Wu et al. 20]. (Solid line) calculations using the mapping strategy. (Dash line) simulations carried out with turbulentInlet boundary condition.

In Fig. 16, it can be seen that close to the nozzle $(x / D<8)$ radial velocity profiles can be accurately reproduced by using the mapping strategy. The OpenFoam boundary condition does not achieve the same accuracy at those distances. Though, after $x / D=8$, the jet simulated with the fluctuating boundary condition has exchanged enough momentum to reach similar profiles than experiments. Therefore this artificial tool proves to be useful if quicker results with slightly poorer accuracy (specially close to the nozzle) are required. The simulation carried out with OpenFoam boundary condition tends to over estimate fluctuations, but it is clear that it depends specially on the fluctuation scale parameter (required parameter of the boundary condition) which has been imposed to be $10 \%$. This parameter could be a key aspect to improve results performed with OpenFoam boundary condition. By reducing this parameter a reduction in velocity as well as in its fluctuation is expected. 
Raúl Payri, J. Javier López, Pedro Martí-Aldaraví, Jhoan S. Giraldo, Effect of turbulent model closure and type of inlet boundary condition on a Large Eddy Simulation of a non-reacting jet with co-flow stream, International Journal of Heat and Fluid Flow, Volume 61, Part B, October 2016, Pages 545-552, http://dx.doi.org/10.1016/j.ijheatfluidflow.2016.06.016.
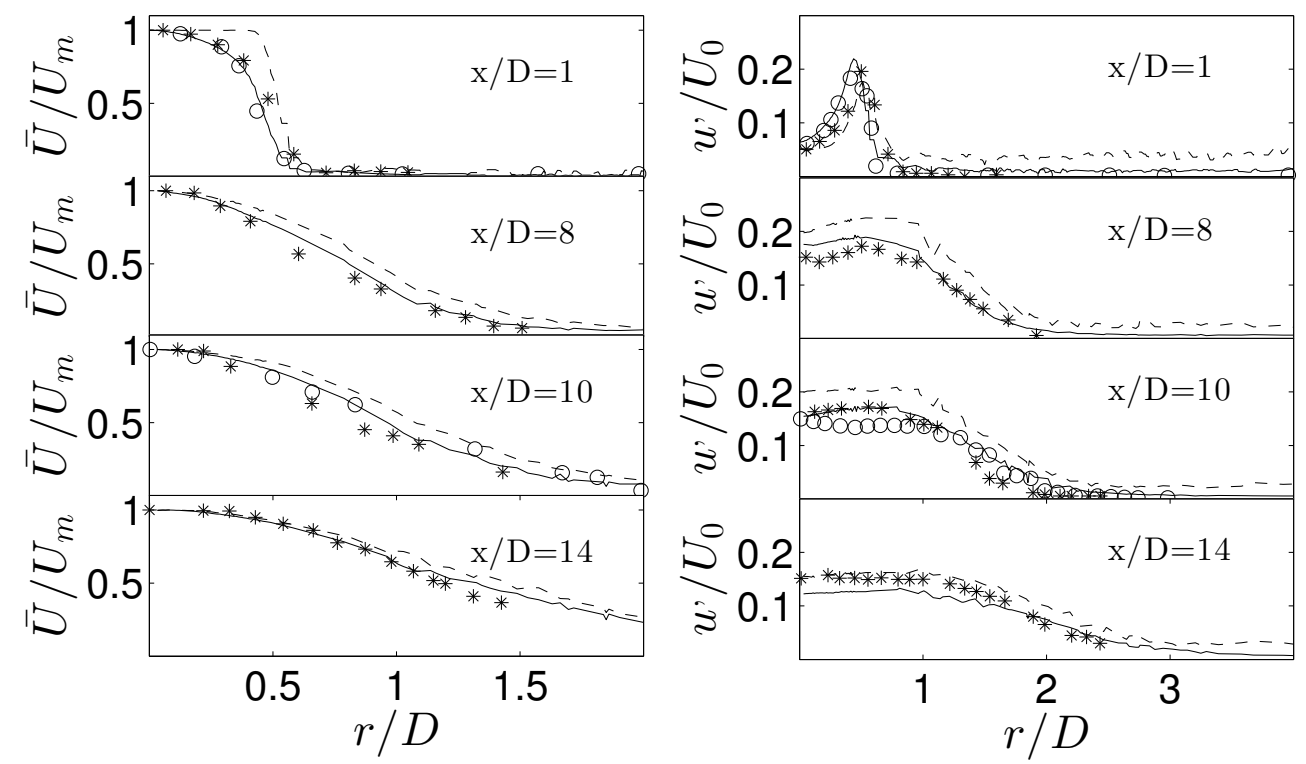

Figure 16: Radial velocity profiles. (Circles) Measurements Wu et al. [20]. (Asterisks) Measurements Cao et al. 21]. (Solid line) calculations using the new boundary condition . (Dash line) simulations carried out with turbulentInlet boundary condition.

\subsection{Effect of turbulent model closure}

In this section, results obtained for the inert jet injected in the coarse mesh, using both sub-grid scale models, SMAG and OEE, are presented. As it has been said before, the OEE model allows coarser meshes, which implies longer time steps with the same Courant number $C_{0}$, hence less computational cost to achieve admissible results. Velocity decay for both models, depicted in Fig. 17, seems to fit properly with the experimental data.

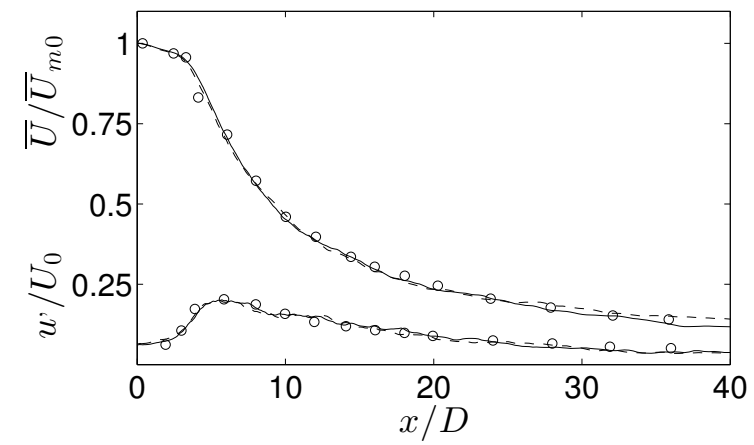

Figure 17: Velocity decay and its fluctuation in axis direction. (Circles) measurements Wu et al. 20. (Solid line) calculations using SMAG model closure. (Dash line) calculations using OEE model closure. 
Raúl Payri, J. Javier López, Pedro Martí-Aldaraví, Jhoan S. Giraldo, Effect of turbulent model closure and type of inlet boundary condition on a Large Eddy Simulation of a non-reacting jet with co-flow stream, International Journal of Heat and Fluid Flow, Volume 61, Part B, October 2016, Pages 545-552, http://dx.doi.org/10.1016/j.ijheatfluidflow.2016.06.016.

Comparison of radial velocity profiles from both sub-grid scale models with experimental data is shown in Fig. 18. Both models show good accuracy in their results. This suggests that it is useful to simulate Cabra-like flames using the OEE model closure. This model is not commonly used for lifted flames according to the literature reviewed in this pa]
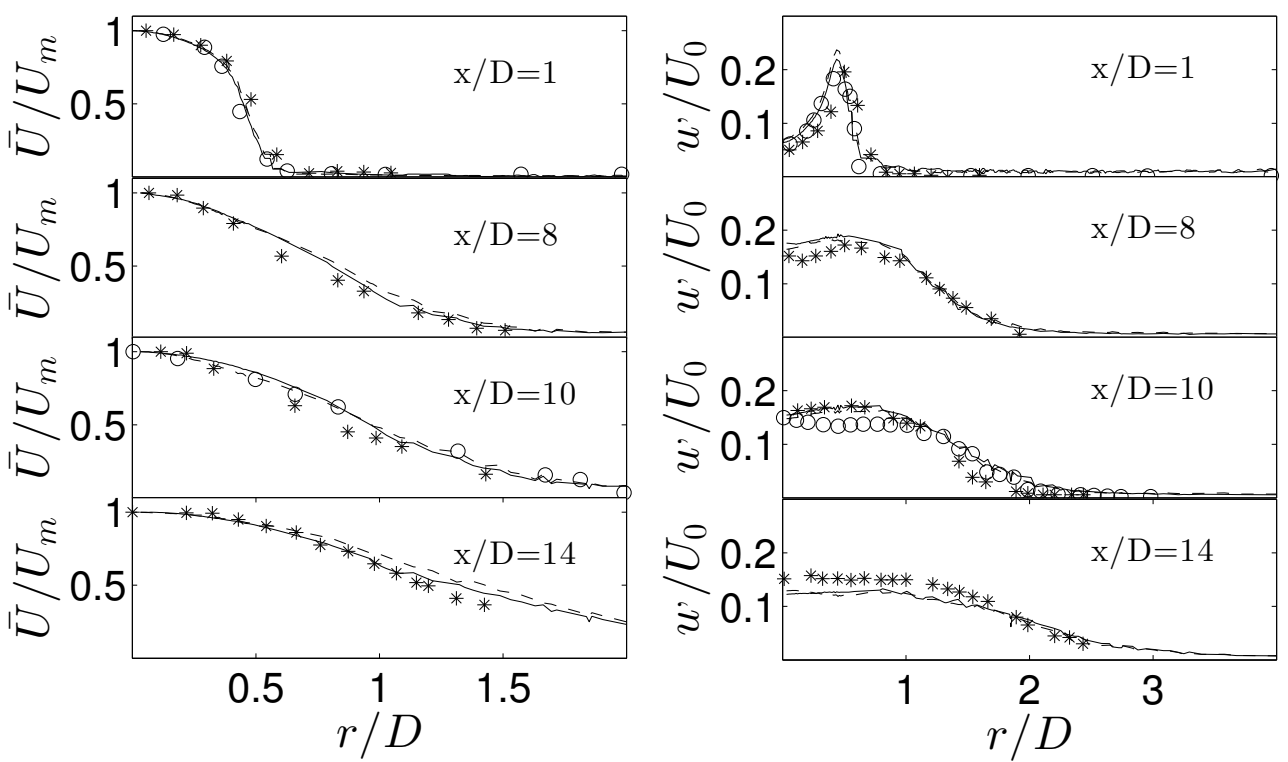

Figure 18: Radial velocity profiles. (Circles) Measurements Wu et al. [20]. (Asterisks) Measurements Cao et al. 21. (Solid line) calculations using SMAG model closure. (Dash line) calculations using OEE model closure.

\subsection{Self-preserving profiles}

Turbulent jets are distinguished by having two main zones according to experimental observations made on mean velocity fields [35]. Near nozzle area, called the flow development region, where there is a potential core surrounded by a mixing layer [21]. In this zone it can be also observed a non-perturbed region, where the axial velocity at the center of the jet barely decreases. The second zone is called the fully developed flow region where the mixing process has reached the whole section and therefore the non-perturbed zone disappears [36]. In this region velocity profiles become self-similar and the jet is considered to be in equilibrium. This means that all radial velocity profiles tends to fall on one single Gaussian curve. Self-preserving profiles obtained with the SMAG model and using the coarse mesh are shown in Figs. 19 to 22 . After $x / D=5$, mean radial velocity profiles achieved the self-preserving zone, whereas this behavior is not appreciated for relative turbulence intensity at the studied time step. 
Raúl Payri, J. Javier López, Pedro Martí-Aldaraví, Jhoan S. Giraldo, Effect of turbulent model closure and type of inlet boundary condition on a Large Eddy Simulation of a non-reacting jet with co-flow stream, International Journal of Heat and Fluid Flow, Volume 61, Part B, October 2016, Pages 545-552, http://dx.doi.org/10.1016/j.ijheatfluidflow.2016.06.016.

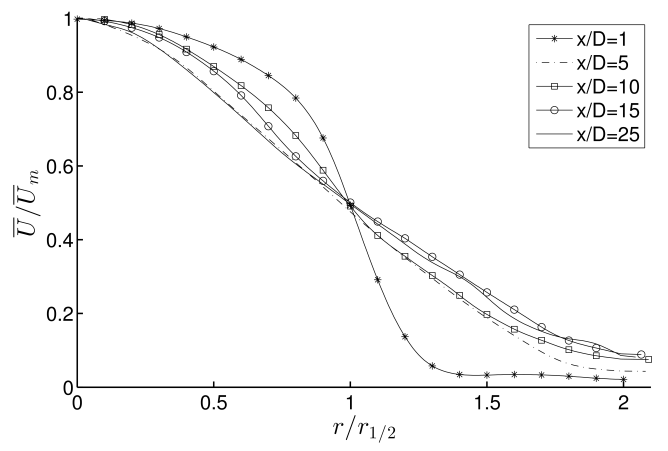

Figure 19: Radial distribution of $U / U_{m}$.

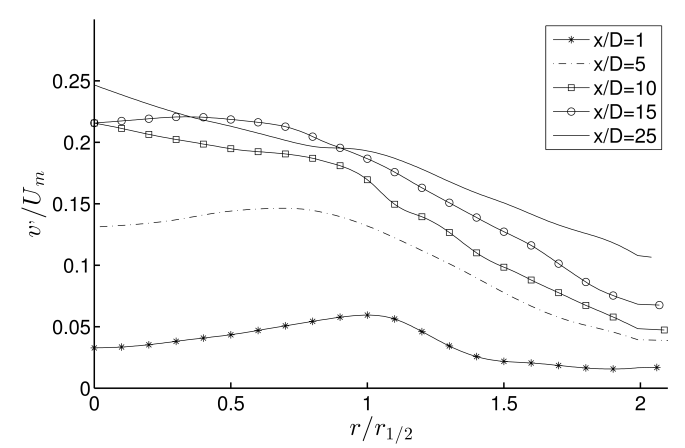

Figure 21: Radial distribution of $v, / U_{m}$.

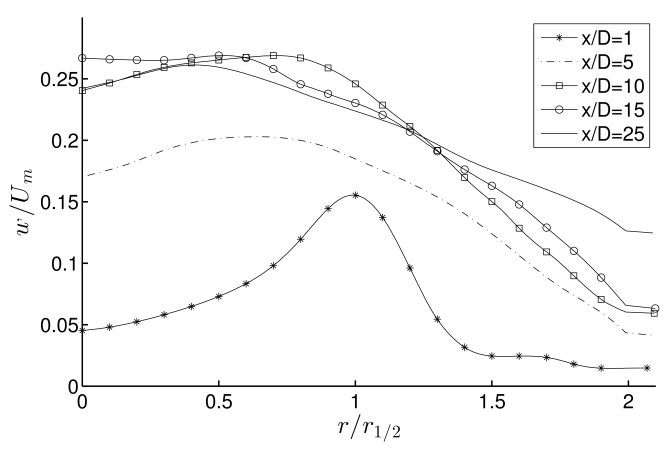

Figure 20: Radial distribution of $w^{\prime} / U_{m}$.

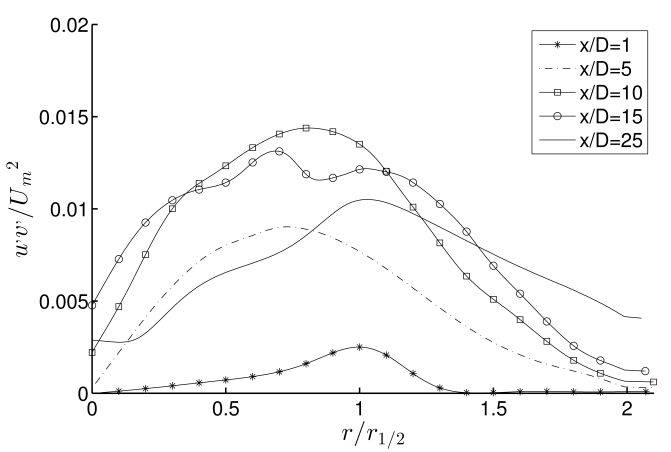

Figure 22: Radial distribution of $u^{\prime} v^{\prime} / U_{m}$.

\section{Conclusions}

In this work, a non-reacting jet with a co-flow stream was computationally studied. The jet was simulated by using two SGS-models (SMAG and OEE), two meshes (coarse and refined) and two inlet boundary conditions (fluctuating and mapping strategy). The main findings of this numerical investigation are as follows:

1. The mapping strategy is able to properly reproduce real turbulence structure. The results obtained from this boundary condition have been more accurate than the ones obtained with OpenFoam's tool for artificial turbulence.

2. The fluctuating boundary condition tool is useful if quicker results are required, but the accuracy is lower specially close to the nozzle. Fluctuations gathered with this condition were higher than the experiments: if this tool is used, a value lower than $10 \%$ for the fluctuation scale should be used.

3. Velocity profiles from simulations performed with both turbulent models seems to properly fit experimental data. This encourage future works related with Cabra's flame to use the OEE model taking into account that this model allows coarser meshes and therefore less computational cost to achieve good results. 
Raúl Payri, J. Javier López, Pedro Martí-Aldaraví, Jhoan S. Giraldo, Effect of turbulent model closure and type of inlet boundary condition on a Large Eddy Simulation of a non-reacting jet with co-flow stream, International Journal of Heat and Fluid Flow, Volume 61, Part B, October 2016, Pages 545-552, http://dx.doi.org/10.1016/j.ijheatfluidflow.2016.06.016.

4. With both meshes (coarse and refined mesh) similar results were obtained. This means that the coarse mesh was fine enough to achieve accurate results.

5. Profiles obtained from SMAG_nbc_c show that after $x / D=5$ radial velocity profiles manifest to be in the self-preserving zone.

\section{Acknowledgments}

This research was performed in the frame of the project "Estudio de la interacción chorropared en condiciones realistas de motor" reference TRA2015-67679-c2-1-R from Ministerio de Economía y Competitividad (Spanish Ministry of Economy). The equipment used in this work has been partially supported by FEDER Project funds "Dotación de infraestructuras científico téctinas para el Centro Integral de Mejora Energética y Medioambiental de Sistemas de Transporte (CiMeT), (FEDER-ICTS-2012-06)", framed in the operation program of unique scientific and technical infrastructure of the Ministry of Science and Innovation of Spain. Jhoan S. Giraldo was supported by a research grant from Generalitat Valenciana (Programa Santiago Grisolia, GRISOLIA/2013/007).

\section{References}

[1] P. Domingo, L. Vervisch, and D. Veynante. Large Eddy Simulation of a lifted methane jet flame in a vitiated coflow. Combustion and Flame, 152(3):415 - 432, 2008.

[2] Pascale Domingo, Luc Vervisch, Denis Veynante, et al. Auto-ignition and flame propagation effects in LES of burned gases diluted turbulent combustion. In Proceedings of the Summer Program, page 337, 2006.

[3] Anne Bourlioux, Bénédicte Cuenot, and Thierry Poinsot. Asymptotic and numerical study of the stabilization of diffusion flames by hot gas. Combustion and Flame, 120(1-2):143 - 159, 2000.

[4] R. Cabra, J.-Y. Chen, R.W. Dibble, A.N. Karpetis, and R.S. Barlow. Lifted methane-air jet flames in a vitiated coflow. Combustion and Flame, 143(4):491 506, 2005. Special Issue to Honor Professor Robert W. Bilger on the Occasion of His Seventieth Birthday.

[5] R. Cabra, J.-Y. Chen, and R.W. Dibble. Simultaneous Laser Raman-Rayleigh-LIF Measurements and Numerical Modeling Results of a lifted turbulent H2/N2 jet flame in a vitiated co-flow. Technical report, NASA, 2002.

[6] Robert L. Gordon, Assaad R. Masri, Stephen B. Pope, and Graham M. Goldin. Transport budgets in turbulent lifted flames of methane autoigniting in a vitiated co-flow. Combustion and Flame, 151(3):495 - 511, 2007. 
Raúl Payri, J. Javier López, Pedro Martí-Aldaraví, Jhoan S. Giraldo, Effect of turbulent model closure and type of inlet boundary condition on a Large Eddy Simulation of a non-reacting jet with co-flow stream, International Journal of Heat and Fluid Flow, Volume 61, Part B, October 2016, Pages 545-552, http://dx.doi.org/10.1016/j.ijheatfluidflow.2016.06.016.

[7] S. Navarro-Martinez and A. Kronenburg. LES-CMC simulations of a lifted methane flame. Proceedings of the Combustion Institute, 32(1):1509 - 1516, 2009.

[8] W.P. Jones and S. Navarro-Martinez. Large Eddy Simulation of autoignition with a subgrid probability density function method. Combustion and Flame, 150(3):170 187, 2007.

[9] Luc Vervisch and Arnaud Trouvé. LES modeling for lifted turbulent jet flames. In Proceedings of the Summer Program, pages 83 - 100, 1998.

[10] S Rigopoulos and S Navarro-Martinez. Large Eddy Simulation of a Turbulent Lifted Flame via Rate-Controlled Constrained Equilibrium. equilibrium, 2:2-2, 2009.

[11] Matthias Ihme and Yee Chee See. Large Eddy Simulation of a turbulent lifted flame in a vitiated co-flow. AIAA Paper, 239:2009, 2009.

[12] Ivana Stankovic and Bart Merci. LES-CMC simulations of turbulent hydrogen flame in a vitiated air co-flow. In 7th Mediterranean Combustion Symposium (MCS-7), 2011.

[13] Ivana Stankovic and Bart Merci. LES-CMC simulations of a turbulent lifted hydrogen flame in vitiated co-flow. Thermal Science, 17:763 - 772, 2013.

[14] A. Banaeizadeh, A. Afshari, H. Schock, and F. Jaberi. Large-eddy simulations of turbulent flows in internal combustion engines. International Journal of Heat and Mass Transfer, 60(0):781 - 796, 2013.

[15] Sin Hyen Kim, Pratik Donde, Venkat Raman, Kuo-Cheng Lin, and Campbell Carter. Large Eddy Simulation based Studies of Reacting and Non reacting Transverse Jets in Supersonic cross flow. American Institute of Aeronautics and Astronautics, 482:111, 2012.

[16] Yang Yang and Søren Knudsen Kær+. Large Eddy Simulations of the non-reactive flow in the Sydney swirl burner. International Journal of Heat and Fluid Flow, 36(0):47 - 57, 2012.

[17] Tommaso Lucchini, Gianluca D'Errico, and Daniele Ettorre. Numerical investigation of the spray-mesh-turbulence interactions for high-pressure, evaporating sprays at engine conditions. International Journal of Heat and Fluid Flow, 32(1):285 - 297, 2011.

[18] N. Peters. Turbulent combustion. Cambridge university press, 2000.

[19] Andreas M. Kempf. LES validation from experiments. Flow, Turbulence and Combustion, 80(3):351-373, 2007. 
Raúl Payri, J. Javier López, Pedro Martí-Aldaraví, Jhoan S. Giraldo, Effect of turbulent model closure and type of inlet boundary condition on a Large Eddy Simulation of a non-reacting jet with co-flow stream, International Journal of Heat and Fluid Flow, Volume 61, Part B, October 2016, Pages 545-552, http://dx.doi.org/10.1016/j.ijheatfluidflow.2016.06.016.

[20] Zhijun Wu, AssaadR. Masri, and RobertW. Bilger. An Experimental Investigation of the Turbulence Structure of a Lifted H2/N2 Jet Flame in a Vitiated Co-Flow. Flow, Turbulence and Combustion, 76(1):61-81, 2006.

[21] Renfeng Richard Cao, Stephen B. Pope, and Assaad R. Masri. Turbulent lifted flames in a vitiated coflow investigated using joint $\{\mathrm{PDF}\}$ calculations. Combustion and Flame, 142(4):438 - 453, 2005.

[22] Eric Pomraning and Christopher J. Rutland. Dynamic One-Equation Nonviscosity Large-Eddy Simulation Model. AIAA Journal, 40(4):689-701, April 2002.

[23] Artur Tyliszczak, DavideE. Cavaliere, and Epaminondas Mastorakos. LES/CMC of Blow-off in a Liquid Fueled Swirl Burner. Flow, Turbulence and Combustion, 92(1-2):237-267, 2014.

[24] U. Piomelli. Large-eddy simulation: achievements and challenges. Progress in Aerospace Sciences, 35(4):335 - 362, 1999.

[25] J. Smagorinsky. General circulation experiments with the primitive equations. Monthly Weather Review, 91(3):99-164, 1963.

[26] L. Chan, C. Chin, J. Soria, and A. Ooi. Large Eddy Simulation and Reynoldsaveraged Navier-Stokes calculations of supersonic impinging jets at varying nozzleto-wall distances and impinging angles. International Journal of Heat and Fluid Flow, 47(0):31 - 41, 2014.

[27] Stephen B. Pope. Turbulent Flows. Cambridge University Press, 2000. Cambridge Books Online.

[28] Raul Payri, Jaime Gimeno, Pedro Marti-Aldaravi, and Gabriela Bracho. Study of the influence of the inlet boundary conditions in a LES simulation of internal flow in a diesel injector. Mathematical and Computer Modelling, 57(7-8):1709 - 1715, 2013.

[29] Wu, Xiaohua, Moin, and Parviz. A direct numerical simulation study on the mean velocity characteristics in turbulent pipe flow. Journal of Fluid Mechanics, 2008.

[30] C. Chin, A. S. H. Ooi, I. Marusic, and H. M. Blackburn. The influence of pipe length on turbulence statistics computed from direct numerical simulation data. Physics of Fluids, 22(11), 2010.

[31] M. Klein. An attempt to assess the quality of large eddy simulations in the context of implicit filtering. Flow, Turbulence and Combustion, 75(1):131-147, 2005.

[32] Jochen Fröhlich and Dominic von Terzi. Hybrid les/rans methods for the simulation of turbulent flows. Progress in Aerospace Sciences, 44(5):349 - 377, 2008.

[33] John Kent. B.E thesis. PhD thesis, University of Sydney, 2003. 
Raúl Payri, J. Javier López, Pedro Martí-Aldaraví, Jhoan S. Giraldo, Effect of turbulent model closure and type of inlet boundary condition on a Large Eddy Simulation of a non-reacting jet with co-flow stream, International Journal of Heat and Fluid Flow, Volume 61, Part B, October 2016, Pages 545-552, http://dx.doi.org/10.1016/j.ijheatfluidflow.2016.06.016.

[34] C. Fureby. Towards the use of large eddy simulation in engineering. Progress in Aerospace Sciences, 44(6):381 - 396, 2008. Large Eddy Simulation - Current Capabilities and Areas of Needed Research.

[35] N. Rajaratnam. Preface. In N. Rajaratnam, editor, Turbulent Jets, volume 5 of Developments in Water Science, pages v - vi. Elsevier, 1976.

[36] C.G. Ball, H. Fellouah, and A. Pollard. The flow field in turbulent round free jets. Progress in Aerospace Sciences, 50:1 - 26, 2012. 